\title{
Test and Analysis of Hydraulic Fracture Characteristics of Rock Single Crack
}

\author{
Juncai $\mathrm{Xu}^{1}, \mathrm{Xin} \mathrm{Xie}^{2 *}$, Chenye $\mathrm{Yang}^{3}$ and Zhenzhong Shen ${ }^{4}$
}

${ }^{1}$ State Key Laboratory of Simulation and Regulation of Water Cycle in River Basin, China Institute of Water Resources and Hydropower Research, Beijing, China ${ }^{2}$ Department of Mechanical and Industrial Engineering, Northeastern University, Boston, MA, USA

${ }^{3}$ Department of Electrical Engineering and Computer Science, Massachusetts Institute of Technology, Cambridge, MA, USA

${ }^{4}$ College of Water Conservancy and Hydropower Engineering, Hohai University, Nanjing, China

\begin{abstract}
Hydraulic fracture can often cause serious disasters, of which the hydraulic fracturing of a single crack is one of the common styles. In the paper, the damage mechanics of the hydraulic fracture are revealed by the hydraulic fracture experiment of the single crack. Mortar is used as a similar material to rock mass, and the hydraulic fracture characteristics experiment was carried out. The hydraulic pressure Pini and the change in water pressure inside the crack were studied. The critical water pressure $P c$ and the failure mode of the specimen were analyzed under different working conditions. Based on the experiment, the expression for the correction coefficient of the crack width $\lambda$ and the failure of the critical water pressure $P c$ were obtained.
\end{abstract}

Keywords: Hydraulic fracture; Internal water pressure; Crack width; Critical water pressure

\section{Introduction}

Hydraulic fracture can sometimes cause serious disasters in projects, such as underground gardening or tunnel construction, were large amounts of gushing water, high rock slopes moving under the action of the groundwater might happen, with the cracking generating a high pressure water supply structure or the reservoir dam due to penetration [1-4]. With the rapid development of the large-scale underground structure and the high dam construction, water conservancy and the hydropower industry need carry out the corresponding hydraulic fracture studies [5-7]. The hydraulic fracturing of single cracks, such as the hydraulic fracturing in oil extraction, hydraulic fracturing in in-situ stress measurements, large segregation of gushing water in underground structures and the hydraulic fracturing of dams. The hydraulic fracturing study focuses on one or more regular cracking in high pressure water flow [8-10]. Hydraulic fracturing experiments are the only effective way to study the hydraulic fracture mechanism $[11,12]$.

In order to study the cracking mechanism of how rock masses crack under high pressure water flows, inspired by these work [13-20], we considered mortar as a cube specimen with a similar material to that of rock masses for studying the hydraulic splitting characteristics, and used water sealer and water pressure loading equipment in a single crack hydraulic fracturing experiment. The critical water pressure $P C$ and the destructive shape of the specimen were analyzed under different working conditions. The water pressure Pini was measured by embedding both the hydraulic pressure sensor and the strain gauge at the $0 \mathrm{~mm}$ and the $20 \mathrm{~mm}$ position from the prefabricated crack tip in order to study the change law of the internal water pressure. Based on the fracture mechanics, the influence of the different prefabricated crack widths and lengths on the failure of the specimen was studied. Finally, the correction coefficient $\lambda$ of the crack width and the critical hydraulic pressure $P c$ were deduced [21-23].

\section{Rock specimen and Hydraulic Fracture Test}

\section{Rock specimen preparation}

All the test specimens were made from the same mix of cement, sand and water (mix proportion=1: 4.559: 0.774). Cement was 32.5\# ordinary portland cement, and the river sand with particle size ranging from $0.3 \sim 0.5 \mathrm{~mm}$ were used. The specimens were made of preformed cracks at different thicknesses and widths by six sizes of steel sheet $(2$ $\mathrm{mm} \times 40 \mathrm{~mm} \times 250 \mathrm{~mm} ; 2 \mathrm{~mm} \times 60 \mathrm{~mm} \times 250 \mathrm{~mm} ; 2 \mathrm{~mm} \times 50 \mathrm{~mm} \times$ $250 \mathrm{~mm} ; 4 \mathrm{~mm} \times 50 \mathrm{~mm} \times 250 \mathrm{~mm} ; 6 \mathrm{~mm} \times 50 \mathrm{~mm} \times 250 \mathrm{~mm})$. When the time reached the initial set, the preformed steel sheet was pulled out of the specimen in order to form one prefabricated crack. In order to measure the crack pressure in this prefabricated crack, the high pressure water pipe with a diameter of $4 \mathrm{~mm}$ was embedded into the side of each mold, to the side of the prefabricated fracture hole, both at $0 \mathrm{~mm}$ and $20 \mathrm{~mm}$. After the specimen was cured, it was connected to the hydraulic pressure sensor connector. Before pouring the cement mortar in the mold, we used the inside of the mold and the steel sheet along with a release agent and filled the mold with the cement mortar and vibrated it. When stripped, the specimen was placed in the standard curing room maintenance. After the test piece was cured for 28 days, the surface of the test piece was polished with sandpaper in order to make the specimen have the surface flatness that was required.

\section{Hydraulic fracture testing}

The hydraulic pressure of the rock specimen was tested in an electro-hydraulic servo pressure test system and was controlled by computer. The specimen was fixed with a water pressure sealing device. The water pressure $P$ was applied to the slab of different widths and thicknesses, with the pressure of the water at a steady speed of $5 \mathrm{rad} / \mathrm{s}$ until the specimen was damaged. The characteristics of the cracks at the joints were studied under different seam widths and seam thickness expansion of the internal water pressure changes. The hydrostatic

*Corresponding author: Xie X, Department of Mechanical and Industrial Engineering, Northeastern University, Boston, MA, USA, Tel: 1-857-265-6740; E-mail: xie.x@husky.neu.edu

Received May 20, 2017; Accepted June 15, 2017; Published June 23, 2017

Citation: Xu J, Xie X, Yang C, Shen Z (2017) Test and Analysis of Hydraulic Fracture Characteristics of Rock Single Crack. Fluid Mech Open Acc 4: 164. doi: 10.4172/2476-2296.1000164

Copyright: (c) $2017 \mathrm{Xu} \mathrm{J}$, et al. This is an open-access article distributed under the terms of the Creative Commons Attribution License, which permits unrestricted use, distribution, and reproduction in any medium, provided the original author and source are credited. 
loading system started from the beginning of the test and collected the external pressure values of the specimen every $1 \mathrm{~s}$. We cured the six cube specimens $(70.7 \mathrm{~mm} \times 70.7 \mathrm{~mm} \times 70.7 \mathrm{~mm}) 28$ days. Table 1 shows two schemes, $\mathrm{A}$ and $\mathrm{B}$, under the two conditions of the prefabricated fractured rock specimen test.

\section{Experimental Results and Analysis}

\section{Variation law of water pressure in cracks}

The crack propagation is reflected by the change in the number of hydraulic sensors at different locations from the tip of the crack. Figure 1 shows the change law of the internal water pressure at different distances from the crack tip at $0 \mathrm{~mm}$ and $20 \mathrm{~mm}$ water pressure sensor.

As can be seen from Figure 1, the width of the crack propagation is small when the water pressure is small. The water pressure sensor near the tip of the crack does not reflect the change. With an increase in water pressure, the first water pressure sensor began to measure when the water pressure increased to $544 \mathrm{~s}$. With the hydrostatic loading device continuing with the increase in water pressure, the cracks continued to expand, and the crack opening width also increased until the water head reached the full head. With the expansion of the crack, the water pressure sensor that was located at a $20 \mathrm{~mm}$ distance from the crack tip appeared numerical when the test time reached $615 \mathrm{~s}$. With the water pressure loading ascending, the measured value continuously increased. However, when the load time reached 663, the water pressure suddenly decreased, and the both sensor measurements also dropped sharply (Figure 1).

Through the analysis of the water pressure measured both at $0 \mathrm{~mm}$ and $20 \mathrm{~mm}$ from the A-1 specimen, it can be seen that the crack width

\begin{tabular}{|l|l|c|c|c|}
\hline \multicolumn{2}{|l|}{ Test scheme } & $\begin{array}{c}\text { Prefabricated crack } \\
\text { length (mm) }\end{array}$ & $\begin{array}{c}\text { Prefabricated } \\
\text { crack width (mm) }\end{array}$ & $\begin{array}{c}\text { Number of test } \\
\text { specimen }\end{array}$ \\
\hline A & A-1 & 50 & 2 & 2 \\
\cline { 2 - 5 } & A-2 & 50 & 4 & 2 \\
\hline & A-3 & 50 & 6 & 2 \\
\hline B & B-1 & 40 & 2 & 2 \\
\hline & B-2 & 50 & 2 & 2 \\
\hline & B-3 & 60 & 2 & 2 \\
\hline
\end{tabular}

Table 1: Rock specimen test scheme.

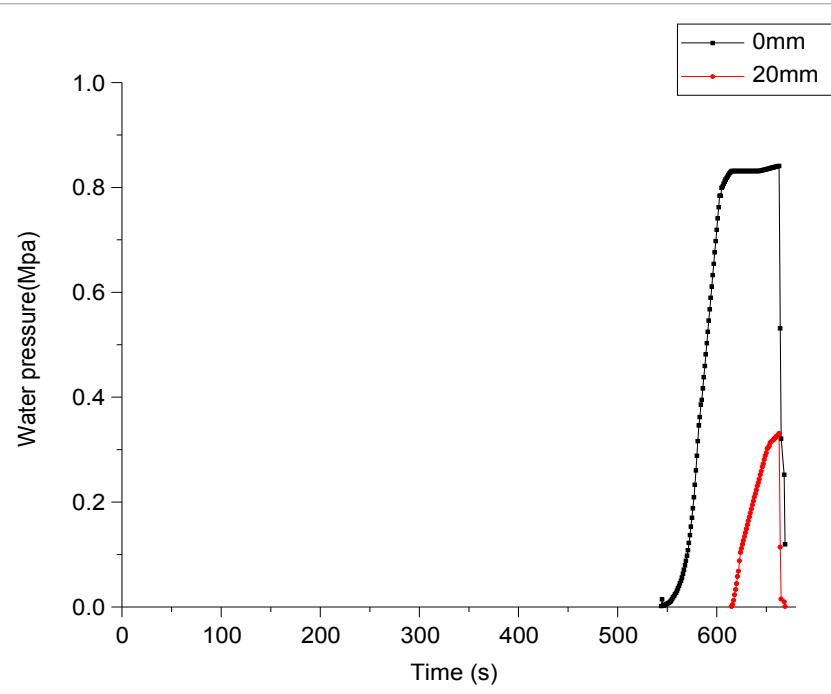

Figure 1: Internal water pressure of A-1 specimen crack. is relatively small during the initial phase of the extensive process of the crack. The pressured water fails to enter the cracks and the water front lags behind the expansion of the dry cracks. However, when the width of the cracks opens up to a certain value, the pressured water will enter the cracks and reach the full head.

\section{Determination of initiation crack water pressure}

Based on the large number of experimental studies performed, the failure form of the specimen is determined by the linear elastic stage before the fracture initiation, the stable expansion stage after the crack initiation, and the fracture failure stage. When the specimen is at the linear elastic phase before the crack initiation, the strain located at the end of the crack is linearly related to the external load, and it increases along with the increase of the external load. Once the cracks begin to grow, the strain near the end of the crack will suddenly decrease with release of the stress. Based on the hydraulic pressure sensor and the location of the crack at the point of change, the initiation time and the load can be determined.

The A- 1 specimen in Table 2 is considered for studying. Table 2 lists parts of the test data for the initiation of the A-1 specimen. Based on Table 2, the water pressure sensor near the position of the prefabricated crack began to show a change when the test time reached $544 \mathrm{~s}$. With the increasing water pressure, the water pressure sensor showed a gradual increase. As the development lagged behind of the expansion of the dry cracks, it was generally assumed that the cracks only began to appear at the 544s mark. When the test time of A-1 specimen reached $541 \mathrm{~s}$, the strain suddenly began to decrease. So the time of the initial crack generation in the A-1 specimen can be considered as $541 \mathrm{~s}$ and a starting pressure of $0.535 \mathrm{MPa}$. The internal water pressure of the initiation crack can be obtained, with the analysis results shown in Table 3.

\section{Determination of critical water pressure}

When the water pressure in the rock specimen reaches the critical water pressure, the specimen will be destroyed. The crack will penetrate through the entire specimen, starting from the crack tip, and the water pressure value $P$ will drop to near zero. In addition, the destruction of the specimen will be accompanied by dull sound and water jets will emerge from the surface of the destruction.

Taken the A-1 sample under the action of the water pressure to analyze it, (Figure 2 and Table 3 ) respectively display the A-1 sample water pressure changes and the destruction of part of the data.

Based on Figure 2 and Table 3, the water pressure went from 0.883 $\mathrm{MPa}$ at 660 seconds up to $0.886 \mathrm{MPa}$ at 663 seconds. However, the water pressure decreased from $0.886 \mathrm{MPa}$ at $663 \mathrm{~s}$ to $0.321 \mathrm{MPa}$ at 665 ,

\begin{tabular}{|c|c|c|c|}
\hline Test time/s & Sensor number $/ \mathbf{k P a}$ & $\begin{array}{c}\text { Crack tip } \\
\text { strain/ } \mathbf{\mu \varepsilon}\end{array}$ & $\begin{array}{c}\text { Water pressure/ } \\
\mathbf{M P a}\end{array}$ \\
\hline 539 & 0 & 6.58035 & 0.533 \\
\hline 540 & 0 & 7.59482 & 0.534 \\
\hline 541 & 0 & 8.02292 & 0.535 \\
\hline 542 & 0 & 6.2418 & 0.535 \\
\hline 543 & 0 & 3.75867 & 0.536 \\
\hline 544 & 0.0016 & 1.50187 & 0.537 \\
\hline
\end{tabular}

Table 2: A-1 specimen initiation crack data record.

\begin{tabular}{|l|c|c|c|}
\hline Time (s) & 660 & 661 & 662 \\
\hline $\begin{array}{l}\text { Water Pressure } \\
\text { (MPa) }\end{array}$ & 0.883 & 0.883 & 0.884 \\
\hline
\end{tabular}

Table 3: Specimen A-1 water pressure. 


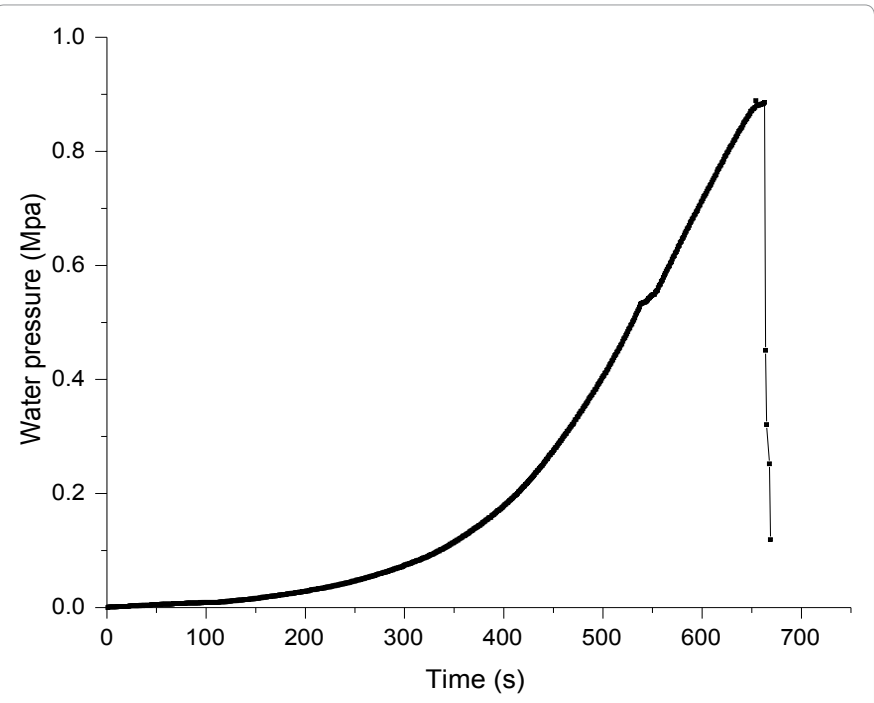

Figure 2: Specimen A-1 water pressure change.

\begin{tabular}{|c|c|c|c|c|c|c|}
\hline Case & Specimen & $\begin{array}{c}\text { Specimen } \\
\text { Number }\end{array}$ & Age/day & ft/MPa & Pini/MPa & Pc/MPa \\
\hline \multirow{2}{*}{$\mathrm{A}$} & $\mathrm{A}-1$ & 2 & 28 & 1.63 & 0.568 & 0.904 \\
\cline { 2 - 7 } & $\mathrm{A}-2$ & 2 & 28 & 1.63 & 0.431 & 0.694 \\
\cline { 2 - 7 } & $\mathrm{A}-3$ & 2 & 28 & 1.63 & 0.283 & 0.441 \\
\hline \multirow{2}{*}{$\mathrm{B}$} & $\mathrm{B}-1$ & 2 & 28 & 1.63 & 0.942 & 1.53 \\
\cline { 2 - 7 } & $\mathrm{B}-2$ & 2 & 28 & 1.63 & 0.568 & 0.904 \\
\cline { 2 - 7 } & $\mathrm{B}-3$ & 2 & 28 & 1.63 & 0.371 & 0.58 \\
\hline
\end{tabular}

Table 4: Critical pressure values for specimens under different operating conditions.

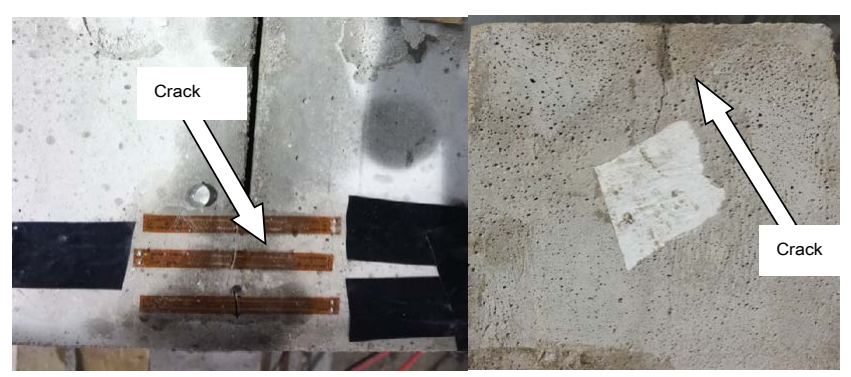

Figure 3: Specimen destruction of the pattern of the photo.

and the specimen damage produced a dull sound during this period. It can be considered that the first damage point occurred at $663 \mathrm{~s}$, when the critical water pressure reached $0.886 \mathrm{MPa}$. Since the measured data between the same set of test pieces are discretized, the mean value was taken as the critical water pressure for the destruction. In both sets of the experimental sketch, A and B under destruction, the critical water pressure results are summarized in Table 4 and Figure 3 shows the fracture along with the prefabricated crack tip through the entire specimen. The split surface and the prefabricated cracks are basically in the same plane.

\section{Critical water pressure theoretical value and crack width correction coefficient}

Table 4 lists the different critical pressures of the prefabricated fractures of length $a$, and the prefabricated fractures of width $b$. Although many studies are focused on I type of the stress-strength factor of the crack found at the center of the slab, and the coefficient of the stress intensity was proposed based on the crack length $a$ as well as on the effect of the specimen scale correction. However, the effect of the crack width $b$ hasn't been studied enough. The crack width correction coefficient is introduced in the research. The stress intensity factor of the type I crack was modified. The expression of the critical water pressure was also provided.

In general, the critical extension conditions for crack instability are [24]:

$$
K=K_{I C}
$$

Where $K$ is the stress intensity factor, $K_{I C}$ is the fracture toughness. When the stress intensity factor $K$ at the crack tip reaches the fracture toughness $K_{I C}$, the unstable failure of the specimen will happen.

Stress intensity factor $K$ at the crack tip is calculated as:

$$
K=\sqrt{\pi a} \cdot \lambda \cdot p \cdot \alpha
$$

Where $a$ is the crack length, $\lambda$ is the crack width correction factor, $p$ is the water pressure acting on the prefabricated fractures and $\alpha$ is the crack length correction factor.

The fracture toughness of the rock specimens $K_{I C}$ are as follows:

$K_{I C}=0.13 f_{t}$

The water critical pressure expression is:

$$
p=\frac{0.13 f_{t}}{\lambda \cdot \sqrt{a \cdot \pi} \cdot \alpha}
$$

The effect correction coefficient, having relation with the crack width $b$ is:

$$
\lambda=f(\eta)
$$

Based on the regression analysis of the correction coefficient $\lambda$ and $\eta$, the expression can be obtained the following way:

$$
\begin{aligned}
& \lambda=0.36 \eta+0.13 \quad(0 \leq \eta \leq 4) \\
& \eta=\frac{b}{B} \times 100
\end{aligned}
$$

The B-1 test specimen is used in order to verify the rationality of the correction coefficient $\eta$ as well as the critical water pressure expression in the given range of the crack width. Using the theoretical formula, the critical hydraulic pressure point can be obtained as $P=1.35 \mathrm{Mpa}$. The result is close to the measured critical water pressure with a relative error of $8.2 \%$. Thus, the specimen theoretical split and the critical water pressure and the correction coefficient of the crack width are correct.

\section{Conclusion}

The change of the water pressure in the cracks is obtained through measuring the hydraulic pressure at both $0 \mathrm{~mm}$ and $20 \mathrm{~mm}$ distance from the tip of the prefabricated crack. The hydraulic front lags behind the extension of the dry crack. During the early stage of the formation of the dry crack, the extensive width of crack is small. With the increase of water pressure, however, the water enters the crack and its width increases more and more. When the crack width reaches a certain value, the head in the crack reaches the full head. According to the analysis of the pressure sensor and the strain gauge located near the crack tip, the initiation crack water pressure Pini can be obtained under the cases A and $\mathrm{B}$. The critical water pressure under failure of the cases A and B was measured by the developed water seal fixture and the water pressure loading equipment. The failure mode of the rock specimen under no tension and compression was obtained. The prefabricated crack tip 
Citation: Xu J, Xie X, Yang C, Shen Z (2017) Test and Analysis of Hydraulic Fracture Characteristics of Rock Single Crack. Fluid Mech Open Acc 4: 164. doi: $10.4172 / 2476-2296.1000164$

passes through the specimen, and the surface of the splitting failure is located substantially in the same plane as the prefabricated fracture. Based on the fracture mechanics and on the correction coefficient of the influence that the crack width has on the stress intensity factor, the expression of the width correction coefficient and the critical hydraulic pressure of the rock fracture are provided.

\section{Acknowledgement}

This research was funded by the Open Research Fund of State Key Laboratory of Simulation and Regulation of Water Cycle in River Basin (Grant No. IWHRSKL-201518).

\section{References}

1. Wang Y, Jia J (2017) Experimental study on the influence of hydraulic fracturing on high concrete gravity dams. Engineering Structures 132: 508-517.

2. Lo KY, Kaniaru K (1992) Hydraulic fracture in earth and rock-fill dams. Canadian Geotechnical Journal 27: 496-506.

3. Liu CH, Xu J, Cao CL (2005) Analysis of bedding-slip failure mechanism of rock slope due to hydraulic drive. Chinese Journal of Rock Mechanics \& Engineering.

4. Tsai VC, Rice JR (2010) A model for turbulent hydraulic fracture and application to crack propagation at glacier beds. Journal of Geophysical Research Earth Surface 115: 227-235.

5. Xu S (2010) Double-K Fracture theoretical analysis and crack width calculation of hydraulic pressure tunnel lining. China Civil Engineering Journal 4: 114-124.

6. Li LP, Li S C, Zhang Q S. Study of mechanism of water inrush induced by hydraulic fracturing in karst tunnels. Rock \& Soil Mechanics 31: 523-528.

7. Zong Li L I, Ren QW (2005) Review of hydraulic fracturing on a single fracture of rock and concrete materials. Hydro-Science and Engineering 1: 67-74.

8. Michael K (2013) Hydraulic fracturing and shale gas extraction. Digestive \& Liver Disease 47: 52.

9. Davletbaev AY, Kovaleva LA (2014) High-viscosity oil flow in a formation with a hydraulic fracture under the action of a high-frequency electromagnetic field. Fluid Dynamics 49: 377-383.

10. Lecampion B (2009) An extended finite element method for hydraulic fracture problems. International Journal for Numerical Methods in Biomedical Engineering 25: 121-133.

11. Beugelsdijk LJL, Pater CJD, Sato K (2000) Experimental Hydraulic Fracture Propagation in a Multi-Fractured Medium: Spe Asia Pacific Conference on Integrated Modelling for Asset Management.
12. Zhang S, Guo T, Zhou T (2014) Fracture propagation mechanism experiment of hydraulic fracturing in natural shale. Acta Petrolei Sinica 35: 496-503, 518.

13. Xie X, Zaitsev Y, Velásquez-García LF, Teller SJ, Livermore C (2014). Scalable, MEMS-enabled, vibrational tactile actuators for high resolution tactile displays. Journal of Micromechanics and Microengineering 24: 125014

14. Yang C, Liu S, Xie X, Livermore C (2016) Compact, planar, translational piezoelectric bimorph actuator with Archimedes' spiral actuating tethers. Journal of Micromechanics and Microengineering 26, 124005.

15. Xie X, Livermore C (2017) Passively self-aligned assembly of compact barre hinges for high-performance, out-of-plane mems actuators. In Micro Electro Mechanical Systems (MEMS), 2017 IEEE 30th International Conference on (813-816). IEEE.

16. Yang Z, Awasthi M, Ghosh M, Mi N (2016) A Fresh Perspective on Total Cost of Ownership Models for Flash Storage in Datacenters, 8th IEEE International Conference on Cloud Computing Technology and Science (CloudCom).

17. Yang Z, Tai J, Bhimani J, WangJ, Mi Ni, et al. (2016) "GREM: Dynamic SSD Resource Allocation in Virtualized Storage Systems with Heterogeneous IO Workloads", 35th IEEE International Performance Computing and Communications Conference (IPCCC).

18. YangZ, WangJ, Evans D, Mi N (2016) "AutoReplica: Automatic Data Replica Manager in Distributed Caching and Data Processing Systems", 1st IEEE International Workshop on Communication, Computing, and Networking in Cyber Physical Systems (CCNCPS).

19. Han Gao, Zhengyu Yang, Janki Bhimani, Teng Wang, Jiayin Wang, et al (2017) "AutoPath: Harnessing Parallel Execution Paths for Efficient Resource Allocation in Multi-Stage Big Data Frameworks", 26th International Conference on Computer Communications and Networks (ICCCN)

20. Yang C, Liu S, Xie X, Livermore C (2015) Out-of-plane translational PZT bimorph actuator with Archimedes' spiral actuating tethers. In: Journal of Physics: Conference Series IOP Publishing 660: 012028.

21. Xie X, Livermore C (2016) A pivot-hinged, multilayer SU-8 micro motion amplifier assembled by a self-aligned approach. In: Micro Electro Mechanical Systems (MEMS), 2016 IEEE 29th International Conference on IEEE 75-78).

22. Xie X, Livermore C (2015) A high-force, out-of-plane actuator with a MEMS enabled microscissor motion amplifier. In: Journal of Physics: Conference Series IOP Publishing, 660: 012026.

23. Yang C, Xie X, Liu S, Livermore C (2017) Resalable, ultra-low leak micro valve using liquid surface tension sealing for vacuum applications. In: Solid-State Sensors, Actuators and Microsystems (TRANSDUCERS), Transducers-2017 19th International Conference on (2071-2074). IEEE.

24. Chang SH, Lee $\mathrm{Cl}$, Jeon S (2002) Measurement of rock fracture toughness under modes I and II and mixed-mode conditions by using disc-type specimens. Engineering Geology 66: 79-97. 